Teknik, 38 (1), 2017, 35-39

\title{
Analisa Metode Pengukuran Berat Badan Manusia Dengan Pengolahan Citra
}

\author{
Fadlur Rahman ${ }^{1}$, Hilman Fauzi ${ }^{*}$, Tauhid Nur Azhar², \\ Ratri Dwi Atmadja ${ }^{1}$, Nasya Ayudina ${ }^{1}$ \\ ${ }^{1}$ Jurusan Teknik Telekomunikasi, Fakultas Teknik Elektro, Universitas Telkom, \\ Jl. Telekomunikasi No. 1, Bandung, Jawa Barat 40257 \\ ${ }^{2}$ Fakultas Kedokteran, Universitas Islam Bandung \\ Jl. Tamansari No. 20, Bandung, Jawa Barat 40116
}

\begin{abstract}
Abstrak
Berat badan merupakan salah satu parameter yang penting untuk mengetahui kondisi tubuh seseorang. Informasi berat badan pada umumnya diperoleh dari pengukuran menggunakan alat timbangan badan. Salah satu metode lain untuk mengetahui berat badan seseorang adalah dengan pengolahan citra. Penelitian ini bertujuan untuk menghitung berat badan dengan menggunakan pengolahan citra. Pendekatan matematis didasarkan pada perhitungan Body Surface Area dan volume elips tubuh manusia. Pengolahan citra yang berupa foto digital diolah untuk menghasilkan informasi mengenai berat badan seseorang pada foto tersebut. Selanjutnya dilakukan investigasi kemungkinan, analisis perhitungan, dan peningkatan akurasi pada sistem. Kinerja dari sistem yang dikembangkan diuji dengan membandingkan hasil perhitungan dengan berat badan hasil dari timbangan badan. Hasil pengujian, analisa, dan akurasi sistem sebesar 95,6\% pada jarak $470 \mathrm{~cm}$ antara kamera dengan objek menunjukkan bahwa metode perhitungan berat badan sangat mungkin dilakukan melalui pengolahan citra dengan berbagai ketentuan serta batasan.
\end{abstract}

Kata kunci: berat badan; body surface area; pengolahan citra

\begin{abstract}
[Title: Analysis of Body Weight Measurement Design System Using Image Processing] Body weight is one of important parameters to determine the condition of a person's body. Information of body weight is usually taken by a measurement scales. One of the other methods to determine body weight is by image processing. This research aims to determine body weight calculation using image processing with various mathematical approach based on a calculation of Body Surface Area (BSA) and the volume of the ellipse for the human body. Image processing from digital photos was processed to get information of one's body weight. Further analysis was done by investigating the possibility, calculation, and analysis of the system's accuracy. Performance of the developed system is examined by comparing the body weight calculation results to the results from a scales. The result of the analysis and the accuracy of calculation system which showed $95 \%$ at $470 \mathrm{~cm}$ distance between the camera and the object of the study shows that weight calculation through image processing is feasible, with various conditions and restrictions.
\end{abstract}

Keywords: body weight; body surface area; image processing

\section{Pendahuluan}

Pada era teknologi ini semua hal yang berhubungan dengan kebutuhan dibuat dalam suatu sistem yang mempermudah manusia dalam melakukan kegiatannya. Terutama kegiatan yang membutuhkan ketelitian yang tinggi atau berulang-ulang seperti mengukur berat badan.

Berat badan merupakan salah satu parameter dalam satuan kilogram (kg) yang digunakan untuk pengukuran tubuh (World Health Organization Expert
Comittee, 1995). Melalui berat badan dapat diketahui berbagai informasi untuk menganalisa kondisi tubuh seseorang seperti Body Surface Area (BSA) dan Body Mass Index (BMI) (Utari, 2007).

Beberapa metode yang telah dilakukan adalah: estimasi perhitungan menggunakan scan data $3 D(\mathrm{Yu}$, $\mathrm{dkk}, 2010$ ); formula Mosteller untuk BSA pada anak (Furqam, dkk, 2010); dan formula The DuBois and DuBois (Verbraecken, dkk, 2006; Shuter dan Aslani, 2000). Yang terakhir merupakan metode yang paling

\footnotetext{
*) Penulis Korespondensi.

E-mail: hilmanfauzitsp@telkomuniversity.ac.id
} 
Teknik, 38 (1), 2017, 36

populer dan banyak digunakan serta telah terbukti secara ilmiah dapat digunakan sebagai acuan yang sesuai.

Selain BSA, kondisi tubuh seseorang dapat dilihat dari BMI. BMI berisi informasi struktur tubuh manusia berupa index dari hasil perhitungan berat dan tinggi badan seseorang. Bipembi dkk. (2015) serta Honade (2013) melakukan penelitian tentang perhitungan BMI seseorang dapat dilakukan dengan input berupa citra menggunakan teknik pengolahan citra digital (image processing) (Munir, 2004; Prasetyo, 2011). Penelitian tersebut telah memberikan informasi penting bahwa ada kemungkinan perhitungan berat badan seseorang dapat dihitung dengan pengolahan citra digital tanpa melakukan pengukuran menggunakan alat timbangan berat badan. Untuk menginvestigasi hal tersebut, perlu dilakukan studi untuk mencari seberapa besar peluang untuk mendapatkan informasi berat badan melalui pengolahan citra digital.

Penelitian ini bertujuan untuk mengukur berat badan seseorang menggunakan teknik pengolahan citra digital yang berbasis Body Surface Area dan formula luas permukaan ruang tabung elips yang dimodifikasi. Input sistem berupa citra tampak depan dan tampak samping seseorang. Adapun output sistem berupa informasi berat badan orang yang bersangkutan. Perhitungan berat badan melalui pengolahan citra dilakukan dengan memodifikasi formula BSA Mosteller karena lebih sederhana dibanding formula BSA DuBois and DuBois yang memerlukan konstanta empiris yang tidak umum (Burton, 2008).

\section{Metode Penelitian}

Penelitian dilakukan dengan melakukan pengujian terhadap 50 objek perempuan dan laki-laki. Data diambil dengan kamera webcam beresolusi 640x480 piksel. Jarak yang digunakan pada sistem ini adalah $470 \mathrm{~cm}$ dan 250 $\mathrm{cm}$ dengan tinggi webcam berjarak $50 \mathrm{~cm}$ diatas permukaan yang sebidang dengan objek. Dalam penelitian dilakukan pengujian dua kondisi berbeda pada saat jarak $470 \mathrm{~cm}$ dan $250 \mathrm{~cm}$. Pada kondisi jarak $470 \mathrm{~cm}$, citra objek akan di capture secara full body atau diambil citranya dari kepala sampai kaki. Pada kondisi jarak 250 $\mathrm{cm}$, citra objek yang akan diambil citranya dari kepala sampai dengan setengah badan dari objek.

Pada penelitian ini, hubungan antara citra untuk mendapatkan nilai BSA adalah menggunakan pendekatan rumus luas permukaan tubuh objek. Penghitungan BSA menggunakan pendekatan tubuh manusia terhadap tabung elips seperti pada Gambar 1.

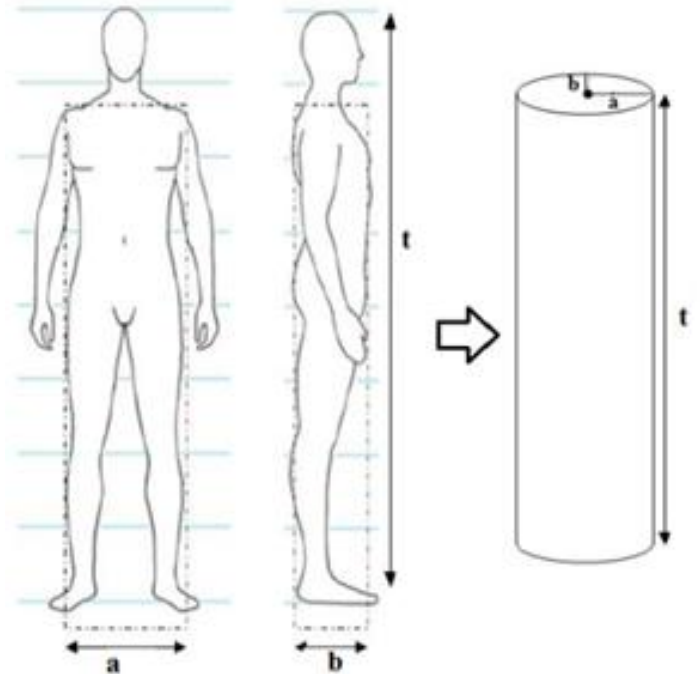

Gambar 1. Pendekatan tubuh terhadap tabung elips.

Pada gambar 1, tinggi, lebar tampak depan, dan lebar tampak samping dilambangkan dengan $\mathrm{t}, \mathrm{a}$, dan $\mathrm{b}$. Untuk mengetahui body surface area dari objek tersebut maka perlu diketahui keliling dan luas dari tabung elips dikalikan dengan beberapa parameter lainnya.

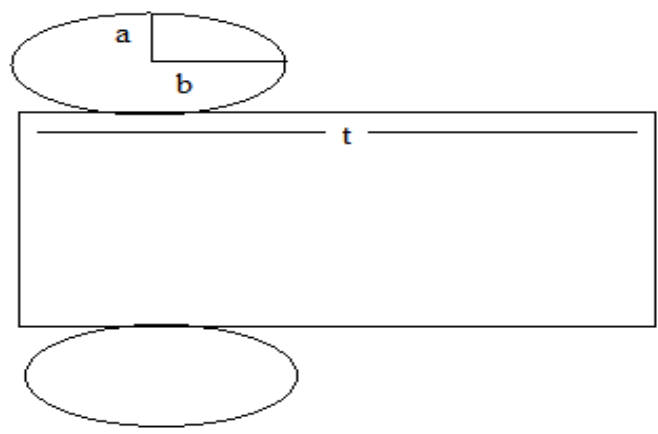

Gambar 2. Bangun ruang tabung elips

Luas elips $=\frac{a, 14}{2} *(a * b)$

Keliling elips $=\frac{a, 14}{2} *(a+b)$

Rumus untuk menggambarkan luas permukaan pada bangun ruang pada Gambar 2 merupakan penggabungan antara luas dan keliling elips seperti berikut:

Luas permukaan $=\frac{a, 14}{2} *(a * b)+\frac{a, 14}{2} *(a * b) * t .$. (4)

Rumus diatas dikalikan dengan beberapa parameter lainnya sehingga didapatkan rumus $B S A$ dengan pendekatan rumus luas permukaan tabung elips seperti berikut: 
Teknik, 37 (2), 2016, 37

BSA $(470 \mathrm{~cm})$

$=\left(\frac{\pi, 24}{z} *(a * b+((a+b) * t))\right) *\left(t_{0, k a n}\right)^{2} * k * 0,0001$

$B S A(250 \mathrm{~cm})$

$=\left(\frac{x_{2} 24}{2} *(a * b+((a+b) *(t * 2)))\right) *\left(t_{\text {vikas }}\right)^{2} * k * 0,0001$.

$\mathrm{t}_{\text {piksel }}=\frac{\text { tinggi badan (cm) }}{\text { tinggi badan (piksel) }}$

dimana $a$ adalah lebar badan depan (piksel); $b$ adalah lebar depan samping (piksel); $t$ merupakan tinggi badan (piksel); $k$ adalah faktor pengali sedangkan $\mathrm{t}_{\text {piksel }}$ adalah konversi piksel ke cm.

Faktor pengali yang digunakan dalam sistem dicari dengan memasukan faktor pengali secara acak sehingga hasil berat badan mendekati dengan berat asli objek. Hingga didapat faktor pengali yang paling mendekat dengan berat aslinya terlihat pada Tabel 1 .

Tabel 1 Faktor pengali sistem

\begin{tabular}{|c|c|}
\hline Jarak (cm) & Faktor Pengali \\
\hline 470 & 0,85 \\
\hline 250 & 0,92 \\
\hline
\end{tabular}

Pada proses selanjutnya, dilakukan penghitungan berat badan menggunakan pendekatan pada rumus Mosteller (Mosteller, 1987) dan rumus BMI yang ditemukan oleh Adolphe Quetelet (Eknoyan, 2007).

BSA $=\sqrt{\frac{\text { Tinggi badan (cmlx Berat badan (kg)) }}{3600}}$

Dari rumus tersebut bisa didapatkan nilai berat badan melalui pendekatan rumus Mosteller dan luas permukaan tabung elips berdasarkan jarak sebagai berikut:

Berat Badan $(470 \mathrm{~cm})=\frac{\left[B S A^{2}\right] * a 600}{\left(\text { tvt }_{\text {piksal }}\right)}$

Berat Badan $(250 \mathrm{~cm})=\frac{\left[B S A^{2}\right] \cdot 3600}{\left([\mathrm{t}+2) * t_{\text {piksal }}\right)}$

Rumus tersebut merupakan rumus yang dipakai untuk penghitungan berat badan yang digunakan sebagai keluaran sistem (Kadir, 2013).

\section{Hasil dan Pembahasan \\ 3.1 Hasil Pengujian Terhadap Pengaruh Jarak}

Pengujian ini dilakukan dengan pengambilan pada jarak $470 \mathrm{~cm}$ dan $250 \mathrm{~cm}$ untuk mengetahui jarak yang optimal pengambilan citra terhadap akurasi sistem. Ukuran citra yang diambil sebesar 640x480 piksel. Sample tabel dan grafik akhir dari hasil keluaran sistem ditampilkan pada Tabel 2.
Tabel 2 Sampel hasil pengujian sistem pengaruh jarak

\begin{tabular}{|c|c|c|c|c|c|}
\hline \multirow{2}{*}{ Data } & \multicolumn{2}{|c|}{ Berat Badan (kg) } & \multirow{2}{*}{ Selisih } & \multirow{2}{*}{$\begin{array}{c}\text { Akurasi } \\
(\%)\end{array}$} & \multirow{2}{*}{$\begin{array}{c}\text { Jarak } \\
(\mathbf{c m})\end{array}$} \\
\hline & Real & Hitungan & & & \\
\hline \multirow{2}{*}{ Citra 1} & 50 & 49,755 & 0,245 & 99,51 & 470 \\
\hline & 50 & 45,376 & 4,624 & 90,75 & 250 \\
\hline \multirow{2}{*}{ Citra 2} & 71 & 72,61 & 1,610 & 97,78 & 470 \\
\hline & 71 & 67,011 & 3,989 & 94,38 & 250 \\
\hline \multirow{2}{*}{ Citra 3} & 55 & 56,673 & 1,673 & 97,05 & 470 \\
\hline & 55 & 56,188 & 1,188 & 97,89 & 250 \\
\hline \multirow{2}{*}{ Citra 4} & 64 & 62,103 & 1,897 & 97,04 & 470 \\
\hline & 64 & 63,948 & 0,052 & 99,92 & 250 \\
\hline \multirow{2}{*}{ Citra 5} & 67 & 67,284 & 0,284 & 99,58 & 470 \\
\hline & 67 & 64,076 & 2,924 & 95,64 & 250 \\
\hline
\end{tabular}

Tabel 3 merupakan sampel data hasil pengujian sistem terhadap pengaruh jarak. Pada tabel tersebut didapatkan akurasi berdasarkan hasil keluaran sistem dibandingkan dengan berat badan konvensional objek pada jarak $470 \mathrm{~cm}$ dan $250 \mathrm{~cm}$.

Tabel 3 Pengaruh jarak terhadap akurasi sistem

\begin{tabular}{|c|c|}
\hline Jarak (cm) & Rata - Rata Akurasi (\%) \\
\hline 470 & 95,63 \\
\hline 250 & 90,91 \\
\hline
\end{tabular}

Tabel 4 merupakan tabel toleransi sistem terhadap pengaruh jarak, yaitu sebesar 4,44\% pada jarak $470 \mathrm{~cm}$ dan $9,53 \%$ pada $250 \mathrm{~cm}$. Tabel tersebut menunjukkan bahwa pengujian pada jarak $470 \mathrm{~cm}$ memiliki hasil akurasi yang lebih baik dibandingkan dengan jarak 250 $\mathrm{cm}$. Hasil pengujian pada jarak $470 \mathrm{~cm}$ nilai akurasinya sebesar 95,63\% dan pada jarak $250 \mathrm{~cm}$ akurasinya sebesar 90,91\%. Hal ini sebebabkan oleh citra yang diakuisisi pada jarak $470 \mathrm{~cm}$ adalah full body atau seluruh postur tubuh objek dari kepala sampai kaki terlihat lebih jelas pada citra sehingga memudahkan dalam cropping. Pada jarak pada $250 \mathrm{~cm}$, sistem hanya mengakuisisi citra secara half body atau setengah badan. Faktor lain yang mempengaruhi adalah ketelitian dalam cropping citra sehingga berpengaruh terhadap hasil keluaran sistem. Pengujian parameter ini telah membuktikan bahwa data ideal untuk dijadikan acuan pengambilan gambar adalah seluruh tubuh. Dengan demikian toleransi dari akurasi metode perhitungan pada data dengan pengambilan yang berjarak $470 \mathrm{~cm}$ memiliki toleransi simpangan sebesar $4,44 \%$ dan $9,53 \%$ pada jarak $250 \mathrm{~cm}$. 
Teknik, 37 (2), 2016, 38

Tabel 4 Toleransi sistem terhadap pengaruh jarak

\begin{tabular}{|c|c|c|c|}
\hline Jarak (cm) & $\begin{array}{c}\text { Rata - Rata } \\
\text { Hitungan }\end{array}$ & $\begin{array}{c}\text { Rata - Rata } \\
\text { selisih }\end{array}$ & Toleransi (\%) \\
\hline 470 & 64,46 & 2,862 & 4,44 \\
\hline 250 & 63,08 & 6,014 & 9,53 \\
\hline
\end{tabular}

\subsection{Hasil Pengujian Sistem Terhadap Pengaruh Jenis \\ Kelamin}

Pengujian lain yang dilakukan adalah pengujian untuk mengetahui apakah jenis kelamin berpengaruh terhadap akurasi sistem. Langkah awal dari pengujian ini adalah mendapatkan akurasi berdasarkan hasil keluaran sistem dibandingkan dengan berat badan konvensional objek pada jarak $470 \mathrm{~cm}$ dan $250 \mathrm{~cm}$ serta jenis kelamin objek, seperti tampak pada Tabel 5 .

Tabel 5 Pengaruh jenis kelamin terhadap akurasi sistem

\begin{tabular}{|c|c|c|}
\hline \multirow{2}{*}{ Jenis Kelamin } & Jarak $(\mathbf{c m})$ & Rata - Rata Akurasi (\%) \\
\hline \multirow{2}{*}{ Laki - laki } & 470 & 96,91 \\
\cline { 2 - 3 } & 250 & 91,74 \\
\hline \multirow{2}{*}{ Perempuan } & 470 & 91,04 \\
\cline { 2 - 3 } & 250 & 88,77 \\
\hline
\end{tabular}

Tabel 6 Toleransi terhadap pengaruh jenis kelamin

\begin{tabular}{|c|c|c|c|c|}
\hline $\begin{array}{c}\text { Jenis } \\
\text { Kelamin }\end{array}$ & $\begin{array}{c}\text { Jarak } \\
(\mathbf{c m})\end{array}$ & $\begin{array}{c}\text { Rata - } \\
\text { Rata } \\
\text { Hitungan }\end{array}$ & $\begin{array}{c}\text { Rata - } \\
\text { Rata } \\
\text { Selisih }\end{array}$ & $\begin{array}{c}\text { Toleransi } \\
\text { Sistem (\%) }\end{array}$ \\
\hline \multirow{2}{*}{ Laki - laki } & 470 & 65,38 & 1,909 & 2,92 \\
\cline { 2 - 5 } & 250 & 65,45 & 5,545 & 8,47 \\
\hline \multirow{2}{*}{ Perempuan } & 470 & 61,96 & 6,289 & 10,15 \\
\cline { 2 - 5 } & 250 & 55,86 & 7,222 & 12,93 \\
\hline
\end{tabular}

Tabel 6 menunjukkan bahwa toleransi sistem sebesar $2,92 \%$ pada jarak $470 \mathrm{~cm}$ dan $8,47 \%$ pada $250 \mathrm{~cm}$ untuk laki - laki serta $10,15 \%$ pada jarak $470 \mathrm{~cm}$ dan $12,93 \%$ pada jarak $250 \mathrm{~cm}$ untuk perempuan.

Hasil pengujian menunjukkan bahwa jenis kelamin laki-laki memiliki nilai akurasi yang lebih baik dibandingkan dengan jenis kelamin perempuan. Pada jenis kelamin laki - laki akurasi yang didapatkan sebesar 96,91\% pada jarak $470 \mathrm{~cm}$ serta akurasi sebesar $91,74 \%$ pada jarak $250 \mathrm{~cm}$. Pada jenis kelamin perempuan didapatkan akurasi sebesar 91,04\% pada jarak $470 \mathrm{~cm}$ serta akurasi sebesar $88,77 \%$ pada jarak $250 \mathrm{~cm}$.

Data tersebut memperlihatkan bahwa akurasi pada jenis kelamin perempuan lebih rendah dibandingkan dengan jenis kelamin laki - laki. Hal ini terjadi karena perempuan mempunyai bentuk postur tubuh yang unik dibandingkan dengan laki - laki. Selain itu, teknik cropping image yang dilakukan sangat berpengaruh terhadap hasil perhitungan piksel. Khusus untuk data objek berjenis kelamin perempuan, proses cropping dilakukan dengan perkiraan fit pada tubuhnya. Hal ini dilakukan kerena objek perempuan sebagian besar menggunakan pakaian yang longgar sehingga pakaian terhitung sebagain bagian dari tubuhnya.
Untuk pengaruh terhadap jarak, akurasi pada jarak yang jauh $(470 \mathrm{~cm})$ lebih tinggi daripada jarak $250 \mathrm{~cm}$ dikarenakan postur tubuh ketika pengambilan di jarak 470 $\mathrm{cm}$ dan di jarak $250 \mathrm{~cm}$ pun berbeda berdasarkan jumlah pikselnya. Hal ini dapat dibandingkan dengan peneitian (Bipembi, dkk., 2015; Honade, 2013) bahwa resize juga mempengaruhi akurasi hasil akhir.

Tabel 7 Sampel pengujian jenis kelamin perempuan

\begin{tabular}{|c|c|c|c|c|c|}
\hline \multirow{2}{*}{ Data } & \multirow{2}{*}{$\begin{array}{c}\text { Jenis } \\
\text { Kelamin }\end{array}$} & \multicolumn{2}{|c|}{ Berat Badan (kg) } & \multirow{2}{*}{$\begin{array}{c}\text { Akurasi } \\
(\%)\end{array}$} & \multirow{2}{*}{$\begin{array}{c}\text { Jarak } \\
(\mathbf{c m})\end{array}$} \\
\hline & & Real & Hitungan & & \\
\hline \multirow{2}{*}{ Citra 1} & \multirow{2}{*}{ Perempuan } & 55 & 57,94 & 94,93 & 470 \\
\hline & & 55 & 62,55 & 87,94 & 250 \\
\hline \multirow{2}{*}{ Citra 2} & \multirow{2}{*}{ Perempuan } & 55 & 56,26 & 97,76 & 470 \\
\hline & & 55 & 49,57 & 90,12 & 250 \\
\hline
\end{tabular}

Tabel 7 merupakan data sampel hasil pengujian terhadap dua objek dengan berat badan yang sama namun hasil keluaran sistem yang didapatkan berbeda antara data 1 dan data 2.

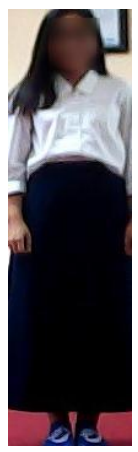

(a)

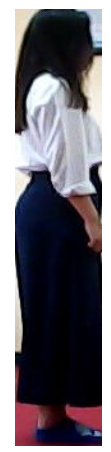

(b)
Gambar 3. Citra 1: (a) tampak depan (b) samping

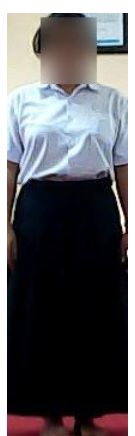

(a)

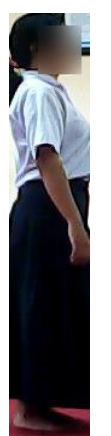

(b)
Gambar 4. Citra 2: (a) tampak depan (b) samping

Gambar 3 dan 4 menunjukkan bahwa kedua objek pada citra tersebut mempunyai berat badan yang sama seperti terlihat pada Tabel 7. Tetapi jika kedua citra tersebut dimasukan ke dalam sistem maka akan menghasilkan keluaran sistem yang berbeda. Objek pada 


\section{Teknik, 37 (2), 2016, 39}

citra 2 mempunyai postur tubuh yang lebih tegak dibanding objek pada citra 1 sehingga keluaran sistem pada objek citra 2 menghasilkan akurasi yang lebih tinggi dibanding objek pada citra 1 .

\section{Kesimpulan}

Pada penelitian ini telah berhasil dikembangkan metode pengukuran berat badan seseorang menggunakan teknik pengolahan citra digital foto postur tubuh seseorang. Metode yang dikembangkan memberikan hasil dengan akurasi 95,6\%. Pendekatan rumus Mosteller yang menjadi dasar dari perancangan metode ini dinilai masih belum cukup sesuai untuk menggambarkan nilai $B S A$ yang sebenarnya khususnya terkait jenis kelamin objek. Berbagai parameter yang mempengaruhi kualitas citra digital yang akan diolah juga menjadi penentu akurasi hasil pengukuran.

\section{Ucapan Terima Kasih}

Terima kasih disampaikan kepada laboratorium Image Processing and Computer Vision (IMV Labs) Fakultas Teknik Elektro Universitas Telkom yang telah membantu terlaksananya penelitian ini.

\section{Daftar Pustaka}

Bipembi, H., Panford, J. K. \& Appiah, O. (2015). Calculation of Body Mass Index using Image Processing Techniques. International Journal of Artificial Intelligence and Mechatronics. 4(1), 1-7. Eknoyan, G. (2008). Historical Note Adolphe Quetelet (1796 - 1874)- the average man and indices of obesity. Nephrol Dial Transplant. 23 (1), 47-51.

Honade, Shrikant J. (2013). Height, Weight, and Body Mass Index Measurement Using Matlab. Diakses dari https://www.researchgate.net/publication/3011975 78_HEIGHT_WEIGHT_AND_BODY_MASS_IN DEX_MEASUREMENT_USING_MATLAB.
Kadir, Abdul. \& Adhi, Susanto. (2013). Teori dan Aplikasi Pengolahan Citra. Yogyakarta: Penerbit Andi.

Karels A.J. \& Cooper, B.R. (2007). Obesity and its role in oral health. IJAHSP. 5(1), 1-5.

Koshimizu, T., dkk. (2012). Basal metabolic rate and body composition of elite Japanese male athletes. The Journal of Medical Investigation : JMI. 59(34), 253-600.

Kuono, Tsutomu, dkk. (2003). Standardization of The Body Surface Area (BSA) Formula to Calculate the Dose of Anticancer Agents in Japan. Jpn J Clin Onco. 33(6), 309-313.

Mosteller, R.D. (1987). Simplified calculation of bodysurface area. N Engl J Med. 317, 1098.

Munir, R. (2004) Pengolahan Citra Digital dengan Pendekatan Algoritmik. Bandung: Informatika.

Prasetyo, Eko. (2011). Pengolahan Citra Digital dan Aplikasinya Menggunakan Matlab. Yogyakarta: Penerbit Andi

Utari, A. (2007) Hubungan indeks massa tubuh dengan tingkat kesegaran jasmani pada anak usia 12-14 tahun. Tesis. Program Pendidikan Dokter Spesialis I Fakultas Kedokteran Universitas Diponegoro.

World Health Organization Expert Commitee. (1995). Physical status: the use and interpretation of anthropometry. Report of a WHO Expert Committee. World Health Organization Technical Report Series. Diakses dari http://apps.who.int/iris/bitstream/10665/37003/1/ WHO_TRS_854.pdf 